\title{
Numerical Reconstruction of the Masina Lekh Hailstorm Event
}

\author{
Ram P. Regmi \\ National Atmospheric Resource and Environmental Research Laboratory (NARERL) \\ Central Department of Physics, Tribhuvan University, Kirtipur, Kathmandu, Nepal. \\ E-mail:ram.p.regmi@gmail.com
}

\begin{abstract}
The atmospheric conditions leading to the hailstorm over the Mt. Masina Lekh $(\sim 1800 \mathrm{~m})$ and its immediate surroundings has been numerically simulated by implementing the Advance Weather Research and Forecasting (WRF) modeling system. The distribution of cloud water-mixing ratio and numerical sounding profiles strongly suggest massive scale hailstorm in and around the Mt. Masina Lekh. The atmosphere over the area was fully saturated with cloud-water mixing ratio exceeding $1.42 \mathrm{~g} \mathrm{~kg}^{-1}$ and the temperature at the top of the Mt. Masina Lekh $(\sim 800 \mathrm{hPa})$ remained close to the freezing and decreased quickly to freezing aloft and reached to $-22^{\circ} \mathrm{C}$ at the top of the cloud around $550 \mathrm{hPa}$. The massive scale vertical convection induced by the Mt. Masina Lekh appears to be one of the main reasons for the occurrences of frequent and localized severe hailstorms over the area.
\end{abstract}

Keywords: Atmospheric modeling, hail, skew-T analysis, supercooled water.

\section{INTRODUCTION}

The Mt. Masina Lekh range suddenly arises from the vast southern plain of Western Nepal at a few tens of meters above the mean sea level (AMSL) to the height of 1800 meters AMSL and then rather steeply descends down to the narrow and east-west elongated river valley in the north. The mountain range is disposed to the very hot climate of the southern plain of Ganga Basin and HighHimalayan climate in the north. Extending for about 65 $\mathrm{km}$ from Palpa in the East to the Dangwang in the west, the range encompasses diverged types of hills, valleys, passes and slopes and hence association of very complex meteorological processes can be expected with it.

One of the most interesting meteorological processes associated with this mountain range and, particularly, the Mt. Masina Lekh is the frequent occurrence of severe hailstorm events. One such event occurred on 16 February 2014. The event of hailstorm of this particular day has drawn our attention and also motivated to explore possible mechanisms of formation and precipitation of hails over the Mt. Masina Lekh range since a light aircraft had met a fatal accident in the Mt. Masina Lekh in the afternoon of that day. The accident investigation report stresses on the bad weather accompanied with thunderstorm, hail and rainfall as described by local eyewitness (GON 2014). However, the interconnection in between the prevailing weather situations including hail and the aircraft accident is not the subject of this paper.

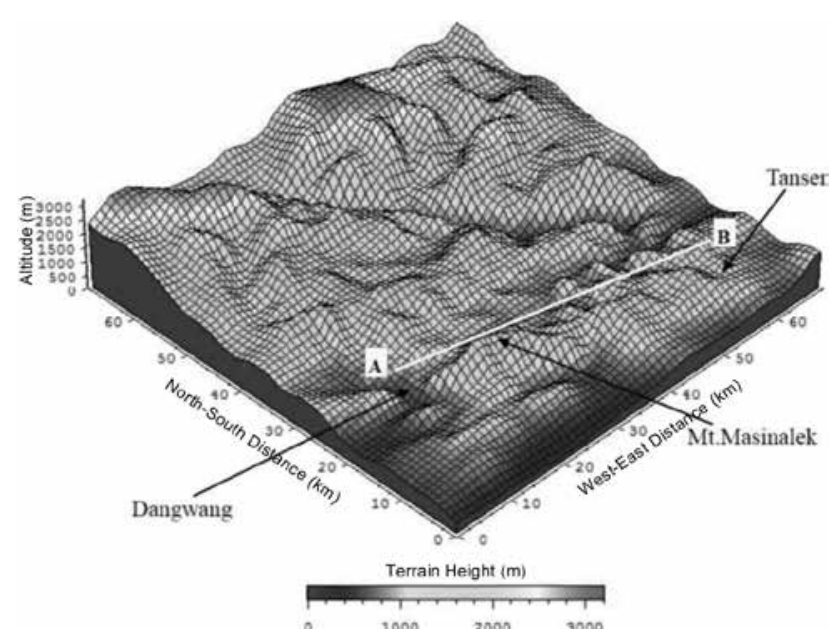

Fig. 1. Bird-eye view of the area in and around the Masina Lekh. Along the line A-B that passes through top of the Mt. Masina Lekh vertical cross-sectional distribution potential meteorological parameters will be examined.

Strong vertical convection of moist air mass often manifests into different types of clouds. Depending upon the prevailing atmospheric conditions, the clouds thus formed may result into light rain or snowfall to devastating thunderstorms with hail or flash flood-producing rain. Hail is a small balls of ice formed in deep convective clouds in extremely low temperatures. Ice grows on initial ice particles by the accretion of supercooled liquid water droplets which freeze on impact (Steiner 1988), pumped into different levels of humidity and water content within updrafts (Nelson 1983) which eventually falls off once 
its weight overcomes the force of the updraft (Knight \& Knight 2001). The size of hail varies from pea shaped to more than 4 inches in their diameter. The difference in humidity and moisture content throughout the cloud layer is the primary reason for varying layers and irregular shapes of hailstones (Nelson 1983).

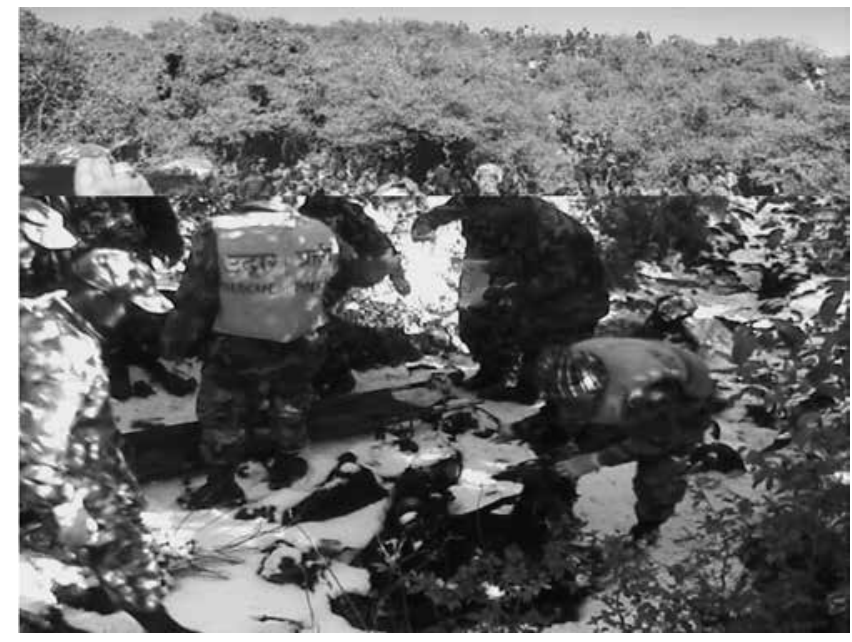

Fig. 2. Pictures of hail deposits over the Mt. Masina Lekh on 16 February 2014 taken in the afternoon of 17 February 2014. Appearances of massive hail deposits until next day afternoon under clear sky may confirm the occurrence of hailstorm events over the area (Picture copied from national news media).

Hailstones grow by wet growth when the corresponding temperature of updraft is between -5 and $-35{ }^{\circ} \mathrm{C}$ where as dry growth occurs with sufficiently low temperatures below $-40{ }^{\circ} \mathrm{C}$ (Brimelow et al. 2002). Changnon (2000) has discussed on localized unstable air masses, vertical shear of horizontal wind, baroclinic instability of frontal systems, lake/topographic effects, and even cloud microphysics triggering hailstorms.

As Nepal is yet to develop upper measurement facilities, bring the country under the umbrella of weather radar echo as well as a good network of surface observatories, study on the hailstorm event in and around the Mt. Masina Lekh need to solely depend on the numerical simulation using advance meso-scale meteorological models.

In this paper, we will examine if the prevailing atmospheric conditions were conducive for hail formation and precipitation in and round the Mt. Masina Lekh. Perhaps, this could be the first initiative to investigate the hailstorm over the area as revealed by numerical simulation.

\section{METHOLODGY}

WRF Modeling System (Michalakes et al. 2001, Skamarock et al. 2008) version 3.5.1 was configured with a triply nested two way interacting mesh having 51 X 51 horizontal grid points for outermost and inner domains with 9 and $3 \mathrm{~km}^{2}$ grid sizes, respectively, whereas the innermost domain was constructed with 70 X 70 grid points of size $1 \mathrm{~km}^{2}$ area (Fig. 3). For each of these domains 35 vertical levels were assigned. The lowest vertical level was set at 27 meters above the ground and the model top was set at $50 \mathrm{hPa}$.

A 48 hours long simulation was performed initializing with horizontal resolution 6 hourly meteorological data from National Centers for Environmental Prediction (NCEP) and the 24 categories land use and 30 second terrain elevation data by United States Geological Survey (USGS) for the period of 0000 UTC 15 February 2014 to 0000 UTC 17 February 2014. The first 24 hours simulations were discarded to allow for model spinup period. The physics options/schemes used in this calculation include Thompson graupel scheme as micro physics parameterization, Unified NOAH land-surface, YSU Planetary Boundary Layer, RRTM long wave radiation schemes, and Dhudhia short wave radiation schemes etc. for all the domains whereas the Kain-Fritsch convective parameterization scheme was turned on only for coarse domain.

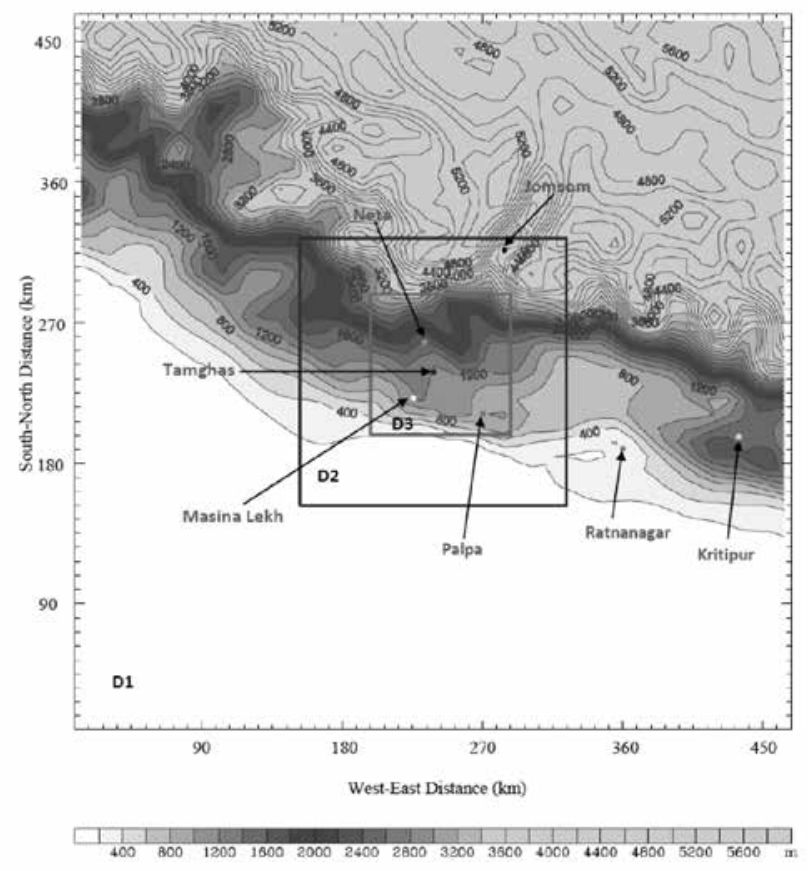

Fig. 3. The triply nested domain configuration used in the simulation. The figure shows the largest (mother) domain in which boxes inside indicate the inner two domains. The three-dimensional topographic view of innermost domain is shown in Fig. 1.

\section{RESULTS}

In order to examine what atmospheric condition were prevailing over the area that led to the occurrence of 
massive scale hailstorm in and around the Mt. Masina Lekh, vertical cross-sectional potential meteorological parameters such as distribution of cloud water mixing ratios, humidity, temperature, wind pattern etc. along the ridge line (A-B in Fig. 1) from Palpa to Dangwang (about $65 \mathrm{~km}$ long) passing through the top of the Lekh and the model predicted soundings close to it were taken into considerations.

Examining the series of cross-sectional distribution of relative humidity for every 15 minutes interval (Figures not shown), it is seen that the atmosphere aloft the top of the Mt. Masina Lekh holds fully saturated air masses during the afternoon and remained not less than $80 \%$ all the time. Likewise, the temperature distribution (Figures not shown), freezing temperature often appears over the top of the Mt. Masina Lekh, particularly, morning and in the late afternoon times. The temperature at a few hundred meters above the mountaintop persistently remained well below the freezing point. The vertical profile of temperature and humidity, thus, appear highly

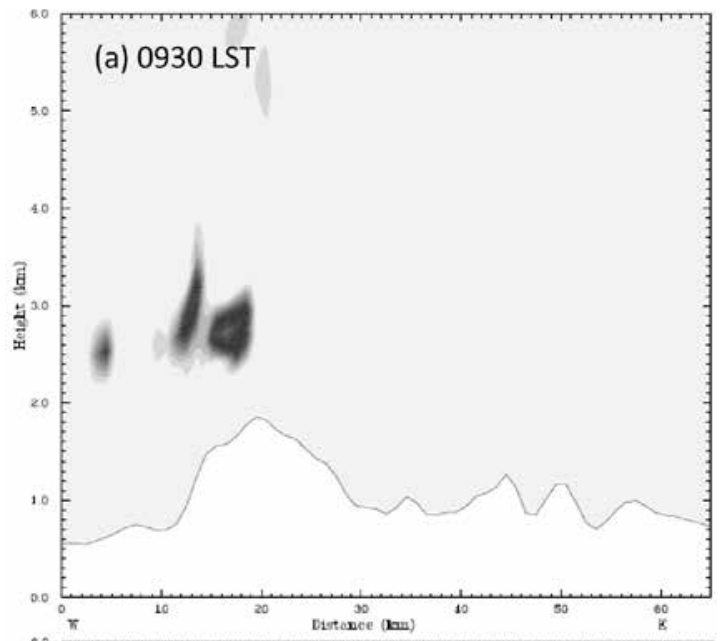

(b) 1330 LST

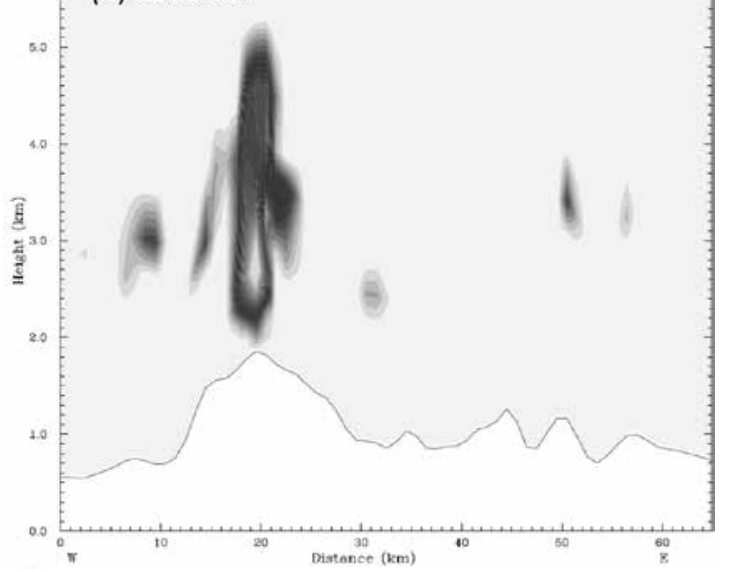

favorable for the formation of hails over the area.

Fig. 4 shows the vertical cross-sectional distribution cloud water-mixing ratio at some representative times of the day. The cloud water-mixing ratio right over the top of the Mt. Masina Lekh appears to be about $0.24 \mathrm{~g} \mathrm{~kg}^{-1}$ during the late morning time (Fig. 4a) and negligible over rest of the places along the cross section. The distribution of cloud water-mixing ratio appears to increase significantly as the afternoon progresses and reaches to about $0.48 \mathrm{~g} \mathrm{~kg}^{-1}$ (Fig. $4 \mathrm{~b}$ ).

Series of bands with high cloud water-mixing ratios begins to commence over the areas east to the Mt. Masina Lekh in the afternoon and reach to maximum both in number of bands and in concentration in the late afternoon (Fig. 4c). The cloud water-mixing ratio during the period reaches to about $1.42 \mathrm{~g} \mathrm{~kg}^{-1}$. It is interesting to note that the sky over Mt. Masina Lekh to Khidim hold the supercooled water up to the height of $3 \mathrm{~km}$ from the top of Mt. Masina Lekh.
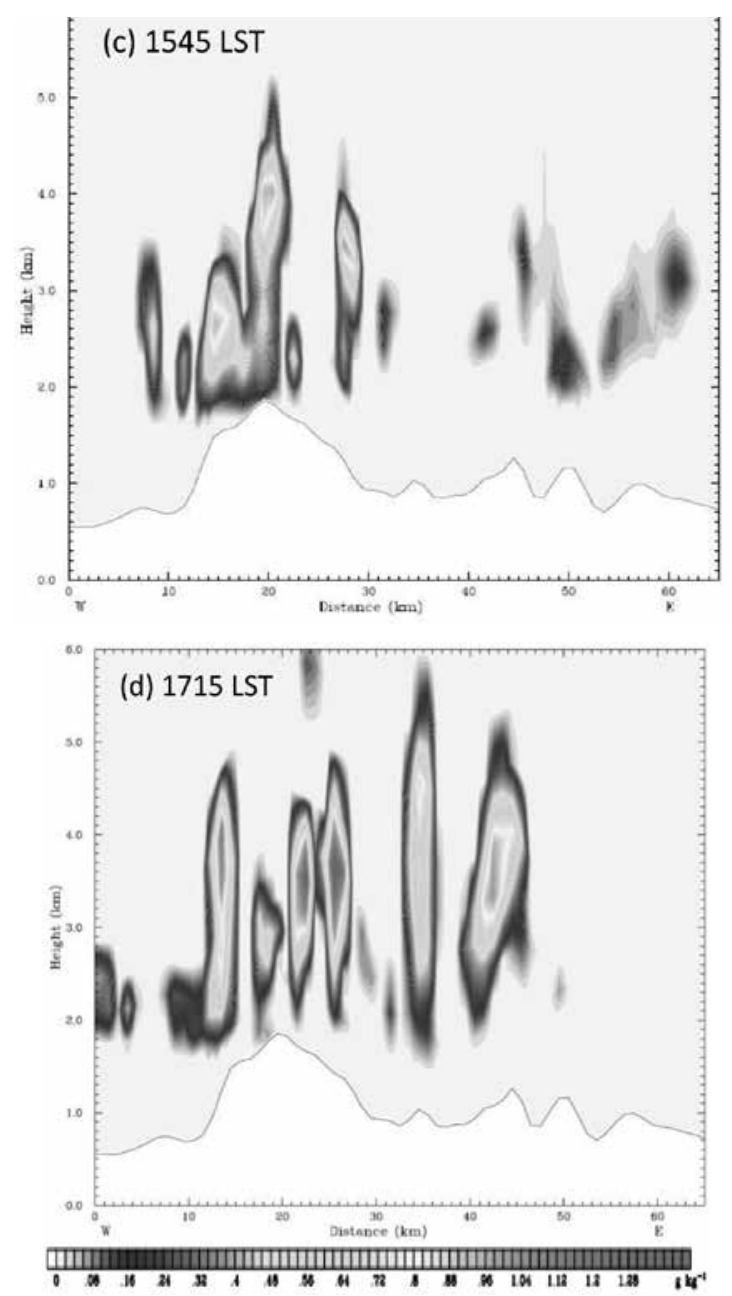

Fig. 4. The cloud water mixing ratio along cross-section A-B at selected time on 16 February 2014. 
The surface and vertical temperature analysis shows that the top of the Mt. Masina Lekh holds the temperature not more than $2^{\circ} \mathrm{C}$ throughout the day with much colder temperature aloft but significantly higher temperature over rest of the cross-sectional area.

The simulated soundings close to the Mt. Masina Lekh (Fig. 5a), i.e., the skew T-lnP chart strongly suggests presence of freezing temperature just above the mountaintop and the atmosphere close to $500 \mathrm{hPa}$ surface is $-22^{\circ} \mathrm{C}$. Moreover, the overlapping of environmental and dew point temperatures in skew $\mathrm{T}-\ln \mathrm{P}$ chart from about 700 to $550 \mathrm{hPa}$ levels clearly indicates that air mass over this thick atmospheric slab is fully saturated. Furthermore, the temperature of this slab of fully saturated atmosphere over Mt. Masina Lekh appears to vary from -4 to $-22^{\circ} \mathrm{C}$.

The temperature, humidity, and the distribution of cloud water-mixing ratio over the Mt. Masina Lekh and the eastern areas from it appear to fulfill the necessary conditions for the development of overcasting cloud and hail with extremely dry atmosphere aloft. However, in the evening the distribution of temperature, humidity, and the cloud water-mixing ratios (not shown) all indicate that the weather over the region greatly improved and the next day was quite clear.

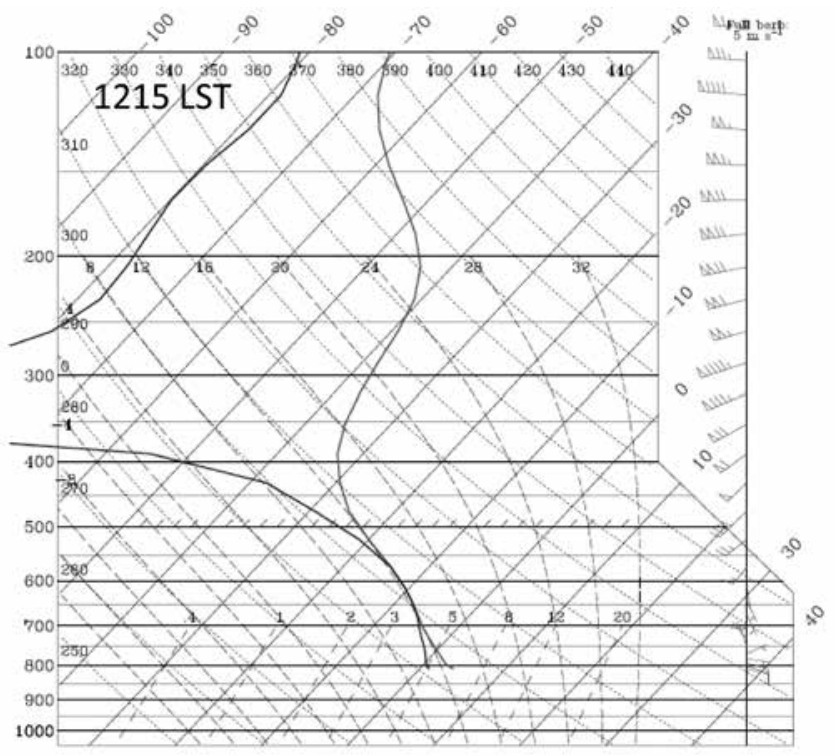

Fig. 5. The afternoontime simulated skew $T-\ln P$ plot over the top of Masina Lekh, Arghakhanchi district.

Since no meteorological stations exist over the area under this study, we could not validate the model predictions except to test the consistencies in between the model predictions, pictures (Fig. 2) and the accident investigation report of the light aircraft (GON, 2014) that has made a detail collection of eyewitnesses of prevailing weather situation over the area in which hailstorm was one of the most reported weather events. The prediction made with WRF model well matched with the available information.

\section{CONCLUSIONS}

The hailstorm event of 16 February 2014 in and around the Mt. Masina Lekh in connection with the fatal aircraft accident has been studied by numerically reconstructing the weather situations using the WRF modeling system. The reconstructed weather situation well reproduced the situation witnessed by the local people as collected by the aircraft investigation commission formed by the Government of Nepal though no meteorological observatories existed in and around the area.

The simulation shows that the cloud water-mixing ratio is very high (about $1.42 \mathrm{~g} \mathrm{~kg}^{-1}$ ) over Mt. Masina Lekh and Khidim during the afternoon and particularly in the late afternoon time. The temperature over the top of the Mt. Masina Lekh is very close to freezing (about $2^{\circ} \mathrm{C}$ ) and immediately goes down below freezing aloft. Simulation also shows that the air mass in between the 700 to $550 \mathrm{hpa}$ is fully saturated and the temperature is below freezing and hence the development of clouds throughout the atmospheric slab in between the 800 to $500 \mathrm{hPa}$ pressure levels can be expected. The cloud top $\left(500 \mathrm{hPa}\right.$ level) temperature appears to be about $-22^{\circ} \mathrm{C}$ and at the bottom it is about $2^{\circ} \mathrm{C}$ (at the top of the Mt. Masina Lekh).

The distributions of temperature from surface to the cloud top and the amount of cloud water-mixing ratio strongly favor the formation and precipitation of hails in and around the Mt. Masina Lekh. However, unlike the case of Mt. Masina Lekh and Khidim areas, the temperature of the lower atmosphere over the rest of the areas appears to be high (about $8^{\circ} \mathrm{C}$ ) enough to melt the hails before reaching the surface. Moreover, the distribution of cloud water-mixing ratio over the Mt. Masina Lekh indicates that there should have been a massive scale vertical convection of moist air mass. The occurrence of massive scale vertical convection over the Mt. Masina Lekh as a result of surface forcings could be the one of the important reasons for the occurrence of localized hailstorms in and around the Mt. Masina Lekh.

\section{ACKNOWLEDGEMENTS}

This study was partially supported by Accident Investigation Commission 2014, Ministry of Culture, Tourism and Civil Aviation, Government of Nepal. The study was possible with the infrastructure developed from the institutional grant research project received from University Grants Commission, Nepal. 


\section{REFERENCES}

Brimelow, J.C. and Reuter, G.W. 2009. Explicit forecasts of hail occurrence and expected hail size using the GEM-HAILCAST system with a rainfall filter. Weather and Forecasting 24: 935-945.

Changnon, S.A. 1978. The climatology of hail in North America. Hail: A review of Hail science and Hail Suppression (Meteorological Monographs) eds. Foote, C.B. and Knight, C.A. American Meteorological Society. 38: 107-128p.

GON 2014. Final report on the accident investigation of 9N-ABB Twin Otter (DHC6/300) aircraft owned and operated by - Nepal Airlines Corporation at Dihidanda, Masinalekh, Argakachi District, Nepal on 16 February, 2014. Commission for the Accident Investigation. $17 \mathrm{p}$.

Knight, C.A. and Knight, N.C. 2001. Hailstorms. In: Severe Convective Storms. (ed.) Doswell, C.A. American Meteorological Society, Boston, Mass. 570p.
Michalakes, J., Chen, S., Dudhia, J., Hart, L., Klemp, J., Middlecoff, J. and Skamarock, W. 2001. Development of a Next Generation Regional Weather Research and Forecast Model. Developments in Teracomputing: Proceedings of the Ninth ECMWF Workshop on the Use of High Performance Computing in Meteorology. (eds.) Zwieflhofer, W. and Kreitz, N. World Scientific. 269-276p.

Nelson, S.P., 1983: The influence of storm flow structure on hail growth. Journal of the Atmospheric Sciences 40: 1965-1983.

Skamarock, W.C., Klemp, J.B., Dudhia, J., Gill, D.O., Barker, D.M., Wang, W. and Powers J.G. 2005. A description of the advanced research WRF NCAR/TN-468+STR. 113p. 